\title{
Tendencies of High-Skilled Migration coming from Romania. Favourable Legislation and Social Policies
}

\author{
Alexandra Vilcu \\ Quality of Life Research Institute (ICCV) \\ Romanian Academy, Bucharest \\ sandravilcu@yahoo.co.uk
}

Abstract

The external migration of a significant part of Romania's high-skilled population is a social phenomenon which became increasingly frequent starting from the 1990s, right after the fall of the communist regime. The basis for this phenomenon consists of several causes: globalization, the strengthening of international economic relations, and later on, Romania's adhesion to the European Union. Research has shown that of all high-skilled population, the professionals who emigrate more frequently consist of engineers, teachers, medical staff, scientific researchers, economists and architects. Besides, the chosen destinations have been variable throughout time. The first phase in time took place in the 1990s, when a large part of the highskilled population chose to emigrate for professional purposes in countries such as The United States of America, Canada, Germany or Israel. The second important phase occurred after year 2000, when the focus was placed on EU countries, especially after Romania's integration. Apart from temporary unqualified migration, the number of high-skilled migrants and those who leave the country to continue their studies also soared. The chosen countries generally include Great Britain, Germany, Belgium, France and Austria. Given these differences in the tendencies of high-skilled migration, this paper will offer an insight on how the phenomenon evolved, and the factors that caused these variations in space and time. Most likely, some of the countries that were preferred have been facilitating the integration of high-skilled immigrants in society, as opposed to unqualified ones, through a selective set of laws and social policies which are meant to favour this social category. Therefore, we will discover and analyze various examples and benefits of legislation and social policies which offered social protection to high-skilledimmigrants in various countries. This paper is made and published under the aegis of the Research Institute for Quality of Life, Romanian Academy, as part of the programme co-funded by the European Union within the Operational Sectorial Programme for Human Resources Development, through the Project for Pluri and Interdisciplinarity in doctoral and post-doctoral programmes. Project code: POSDRU/159/1.5/S/141086

.Keywords: High-skilled migration, Romanian society, Romanian state, Immigration policies, Immigration laws, EU integration.

\section{Introduction and Methodology}

The departure point for this paper is the overall image of the Romanian outgoing migration phenomenon and its phases. Following the main findings of the research, there have been significant differences across time, during the past 25 years, and therefore a more in-depth study of what lies beneath these variations in migration tendencies is necessary. After offering a general insight, we will point towards the specific case of high-skilled Romanian migrants. As I mentioned above, this social issue gradually increased in significance for the Romanian society at the beginning of the 1990s. We will look at the evolution of this phenomenon in our country throughout the years, as well as the purposes of emigration, and especially the countries of destination. The chosen destinations vary significantly, also according to the level of professional qualifications of the subjects.

As a case study, I chose the European Union, and five of its countries, with different types of immigration regulations and Romanian-originating migration patterns. My motivation lies within the high growth in number of EU member countries, which multiplied from 15 to 28 in less than 10 years, but also because there is a permanent struggle between the request for an homogeneous set of immigration policies and the desire to keep a locally-specific regulation. Although the employment restrictions for Romanian workers have just been removed since the beginning of this year, it is still to early to draw conclusions upon the results of this major change. However, the recent past is still actual and with visible consequences in the imprint of Romanian immigration in each country. 


\section{An Outline of Migration originating from Romania and the Involvement of the Romanian State}

Regarding general migration tendencies, sociologist Dumitru Sandu1 has identified three major time phases in Romania's recent history, until year 2006:

$1990-1995-3 \%$ emigration rate; of the total number of departures, 5 countries were exceeding the $7 \%$ percentage: Israel, Turkey, Italy, Hungary and Germany.

$1996-2001-7 \%$ emigration rate; to the countries of the first phase, migrants start choosing Canada, the United States of America and Spain.

$2002-2006-28 \%$ emigration rate; this phase is marked by the free circulation within the Schengen area, causing a massive concentration of temporary work migration, the main destinations being Italy and Spain.

Migrants' level of education also differs amongst these three phases. Our area of interest being the high-skilled ones, also D. Sandu mentions that Romanian migrants with higher education who left the country were higher in number (17\%) during the first time phase, lowering to $9 \%$ in the second phase and further to $7 \%$ in the third phase 2 .

To these original phases, a 4th phase could be easily added, after year 2007, representing Romania's integration in the European Union. According to a study published by the Soros Foundation, entitled Al patrulea val: migratia creierelor pe ruta Romania-Occident (The Fourth Wave: the Brain-Drain on the Romania-West Route), this fourth phase of emigration is dominated by the migration of medical staff more than any other professional categories3.

The fall of the communist regime has had a major influence on the way the Romanian state has been controlling outbound migration. Its role as a social actor in the process of the migration of the Romanian population has changed radically. If before 1989 there was a strict controlling procedure upon departure from Romania and during the period of residence abroad, after the Revolution Romanian citizens were free to travel for any purpose, restriction being eventually imposed by the countries of destination, and being variable from country to country. The role of the state of destination took over the most consistent part of the situation, especially before 2007.

As restricting and blocking migration was no longer an issue, the role of the Romanian state evolved, or should have evolved towards meeting the needs of and offering social protection to Romanian migrants or aspiring migrants, also limiting possible negative occurrences on foreign territory. in a study entitled Politici si institutii in migratia internationala. Migratie pentru munca din Romania 1990-2006 (Policies and Institutions in International Migration: Migration for Work from Romania 1990-2006), authors Monica Serban and Melinda Stoica mention four different types of regulations designed by the Romanian state4:

a) general regulations concerning the departure from the country;

b) general regulations concerning receiving Romanian citizens upon return on Romanian territory;

c) general regulations for the social protection of Romanian citizens living abroad;

d) specific regulations, appeared as a reaction to the recruitment policies of other states.

Taking into consideration the most common migration purpose, namely labour, the same study identified and defined various migration itineraries, according to the presence or absence of mediation between a potential migrant in search for work and the foreign employer, as well as the nature of such mediation. As we are interested only in legal migration, the itineraries in our area of concern are of three types 5 :

Privately mediated migration - special human resources companies act as a link between the Romanian citizen in search for work abroad, and the foreign employers, seeking to balance work offers and requests. This mediation method appeared in the early 1990s, with the main destination being Israel. The disadvantage of this type of private mediation was the limited capacity of the mediating company to interfere in case of conflicts or abuse in the country of destination, which, in the case of state mediation, these issues would have been handled differently.

State mediated migration - minimal until 2002, when the National Office of Workforce Recruitment and Placement (ONRPFMS) entered the workforce mediation market.

1 Sandu, D. (2010), p. 87

2 Sandu, D. (2010), p. 93

$3 \quad$ Ulrich et al. (2011), p.14

$4 \quad$ Serban and Stoica, 2007, p. 5

5 Serban \& Stoica, 2007. p. 10 
Non-mediated legal migration - apparently the most common migration itinerary used amongst high-skilled migrants, a method which involves the aspiring migrant getting directly in contact with the employers of the desired country of destination.

Therefore, considering non-mediated migration as the main choice of the high-skilled group, we draw the conclusion that these targeted countries of destination already had a very specific and transparent set of policies as far as highly qualified workforce was concerned. However, given the fact that some countries were preferable compared to others, an analysis of the reasons behind these preferences is required.

\section{Countries of Destination, the European Union and Immigration Policies}

Taking a look at the global picture, it is obvious that each country has a specific pattern as far as inbound migration is concerned. Some states are more prepared to deal with immigrants than others, just as well as some of them are more selective regarding the quality of immigrants they are willing to accept. Each state has the duty to protect itself from illegal immigration, which might become the basis for criminality or might become detrimental to the native population, especially in those countries which already have their fair share of economic and social problems, such as unemployment. This discourse applies especially to the non-EU context, which, for Romanians and their countries of choice, include EU countries before 2007 and in some cases before 2014, as well as North American countries to this day. The solution lies in establishing a set of immigration policies which ensure a careful selection of immigrants allowed to settle in those specific countries, with evident focus on the highly qualified ones, who can bring a significant contribution in the economic and social life of the country of destination. in the study entitled "Policy Primer: Selecting the Best and Brightest", by Lucie Cerna, published in The Migration Observatory at the University of Oxford in 2011, the author refers to the human capital approach, which defines the strategies of some developed countries to accept immigrants not based on employment shortages and firm job offers, but with the aim "to increase the skills and knowledge based on a country's workforce to promote innovation, productivity growth, and ultimately economic growth and national competitiveness".1

Despite its core values, the European Union has taken into consideration the asset of human capital only in some cases. EU membership, and immigration in this context, should mean free circulation on the labour market. in the discussion paper High-Skilled Immigration Policy in Europe, written in 2010 by Martin Kahanec and Klaus Zimmermann, and published by The Institute for the Study of Labor (IZA), the authors recognize the development of the ability to manage the flow of migration as an enormous challenge for EU countries, especially those who do not have enough immigration history on their territory. $2 \mathrm{~A}$ high amount of attention is drawn to the lack of a consistent and uniformed EU immigration strategy, given the fact that policies still vary from country to country, and policies aimed at high-skilled migrants have only been recently implemented. Besides, administrative barriers are still an issue when it comes to migrating from one country to another the problem shows when it comes to transferring social security benefits, such as pension and health insurance, different taxation systems, or cross-national mortgage policies.

On the other hand, as far as Romanian workers were concerned, not all older member states have adhered to this principle from the beginning of Romania's EU membership. in fact, only on the 31st of December 2013 all work restrictions which were applied to Romanian citizens on the EU territory were abolished. The last 9 countries who were still placing restrictions were: Belgium, Germany, Ireland, France, Luxembourg, Malta, the Netherlands, Austria and the United Kingdom. Spain, which had abolished restrictions a longer while before, had reintroduced them in August 2011, for a period of a just over one year, due to high unemployment issues that Spain was facing. By confronting this list with the general information regarding high-skilled immigration coming from Romania, we can notice that some of these "not fully open" countries, are also some of the preferred destinations for high-skilled Romanian workers, such as the United Kingdom and Germany. This leads us to believe that it is precisely the existence of these restrictions, combined with high-skilled immigration facilitating policies, that have ensured keeping the inflow of immigrants to a higher standard. On the other hand, countries which have been less restrictive, such as Italy or Spain, but which, at the same time, have received a very high number of Romanian immigrants, have also been mostly targeted by under-qualified workforce and also fell prey to Romanian-originating criminality.

This is why I have attempted to give a parallel outline of five EU countries frequently chosen by Romanians, with an insight of their immigration policies aimed at high-skilled immigrants, if these were present. The policy outline of each country (apart from Italy) is present in the aforementioned document published by IZA.

$1 \quad$ Cerna, 2011, p. 2.

$2 \quad$ Kahanec and Zimmermann, 2010, p.5 


\section{Germany}

On the 1st of January 2009, Germany enforced its legal regulation aimed at high-skilled migrants, consisting of free mobility and labour market access for immigrants in possession of a university degree, and also for their families. Work permits must generally be issued by Germany's Federal Employment Agency upon the existence of a firm job offer, however, in the case of high-skilled migrants, the consent of the State in order to work in Germany. Most high-skilled immigrants living in Germany include scientists, teachers, researchers, but also specialists and managers with relevant work experience. Self-employment work permits are given "if the proposed business is expected to have a positive impact on Germany's economy, meet specific local needs and have at least secured financing or is expected to generate at least 250.000 Euros of investment and create a minimum of 5 jobs."1 Moreover, all applicants should acquire knowledge of German language and culture.

\section{France}

The French state is issuing two types of work permit: temporary and permanent. However, the selection process for the assignment of the full work permit (with no time limit), is based on criteria which are favourable to high-skilled immigrants. They must be in possession of a university degree, work in a managerial position or equivalent high-level professional role, being also required to earn at least 3.835 Euros per month, which equals the salary of a French citizen in an analogue position. in the case of self-employed foreigners, applicants must make proof of a firm intention and realistic capacity to generate income in the country. Although France has been less affected by criminality caused by clandestine Romanian immigrants, their radical actions has somehow inflicted caution into those emigrating to France in search for a less-thanhonest life.

\section{Italy}

Although targeted by a very high number of Romanian immigrants, most likely for linguistic and cultural reasons, Italy does not have immigration policies designated for high-skilled immigrants, the Italian state focusing mainly on the work fields in which it had a shortage of Italian employers, and most Romanian workers entered the sectors of constructions, agriculture and domestic work. in order to acquire a residence permit in Italy, one must make proof of a location contract (property buying or renting), a proof of the purpose of stay, in the form of a work contract, a business start-up document, or school/university admission document. Also a bank statement as a proof of having enough funds to support oneself is preferred. However, flaws in the legal system caused immigrants who did not fulfill these criteria to find alternative ways to remain on the Italian territory, although in a clandestine manner.

\section{The United Kingdom}

Before 2008, the United Kingdom had the rule of issuing work permits based on applications made on behalf of the foreign worker by the employer, stating that there are no suitable British citizens able to carry out the specific job. in 2008, the UK implemented a points-based method based on five categories of workers, the first category referring to high-skilled immigrants, entrepreneurs, investors and graduate students, with or without an already-made job offer. Applicants must score a minimum of 75 points. The number of points are distributed amongst various criteria. for example, the higher the level of study (Bachelor Degree, Masters, PhD), the higher the number of points. Also, the younger the applicant, the higher the score, as applicants under the age of 28 are given additional points. Prior work experience, qualifications obtained in the UK, proven proficiency in the English language (owning an internationally-recognized language certificate, university studies taught in English, or origination from an English-speaking country), as well as a proven capacity to support oneself financially also count on the points' scale.

\section{Spain}

Spain, just like Italy, does not have a specific policy for high-skilled immigrants. Work permits are of two types. Type A is aimed at workers who represent a company from their home country, but work in a host company on the Spanish territory for a limited amount of time, has a duration of maximum 9 months, and workers must prove 6-12 months of experience with the company which delegates them to Spain. Type B work permit is for foreigners who are directly employed by a Spanishbased company, has the duration of maximum 12 months, and, although application is made by the employer, renewal requests can also be made by the immigrant employee. in addition, each year the Spanish National Employment Institute issues a centralized list for the entire country, meant to inform in which occupations and areas of the country immigrants are particularly needed. Although not exclusively, this policy is aimed also at high-skilled immigrants and entrepreneurs.

${ }^{1}$ Kahanec and Zimmermann, 2010, p.14 


\section{Conclusion: what Lies ahead for Romanian Immigrants in the EU?}

As we can see, the EU has not been having a set of policies and legal regulations applicable in each country, and each country functions by its own system, which may or may not be similar to the others. for Romanian immigrants, these regulations are no longer applicable since the beginning of this year. However, during over 20 years of partial or total restriction, each EU country has created its own pattern and reputation as far as foreign immigration is concerned. Therefore, if a certain country has been attracting a specific type of immigration, things are not very likely to change, especially now, when the freedom of mobility and work has increased dramatically. It is also argued that all EU countries should take on board the responsibility and be legally and administratively prepared for any type of migration, not just the high-skilled one. in theory, we can even say that the status of EU citizen is somehow becoming a concrete fact instead of an unrealistic dream, although there are still many issues that should be worked on. Moreover, we could even state that "immigration" is no longer an appropriate term in the context of EU borders. It is still early to notice any concrete trends in migration, or whether or not migration patterns and destinations have changed, or will change for Romanians.

Far from being exhaustive, and in the light of recent changes in EU regulations, this paper is mainly intended to raise various questions to keep in mind for future research, policy making, and integration-related programmes:

Will the targeted countries remain the same within the EU, according to the reputation they created for themselves in terms of the already-existing communities and categories of Romanians living and working there?

Will Romania suffer even more because of the brain-drain phenomenon? If so, to what extent and in which professional areas?

Would countries to which the access has been restricted so far, such as the UK, become the new destination of Romanians living until now in Italy or Spain?

Will the absence of actual immigration policies applicable to Romanians give birth to other less-official methods of keeping immigrants at bay, from employment bias to creating extreme nationalist movements? If so, what could be done to prevent that?

Last but not least, how could the public opinion be influenced towards seeing immigration as something inevitable, but definitely advantageous for economic and demographic development, but also cultural enrichment?

The following one or two years are bound to be a significant period of time to watch social changes unfold, and provide answers to the questions above.

\section{BIBLIOGRAPHY}

[1] Cerna, Lucie (2011), "Policy Primer: Selecting the Best and Brightest" in The Migration Observatory, University of Oxford, Oxford

[2] Gaffuri, Luigi and Pittau, Franco (ed.) (2012), 1951-2011: Migration in Italy between Past and Future, Idos Edition, Rome.

[3] Kahanec, Martin and Zimmermann, Klaus (2010), High-Skilled Immigration Policy in Europe, Institute for the Study of Labor, Berlin.

[4] Sandu, Dumitru (2010), Lumile sociale ale migratiei romanesti in strainatate, Polirom, lasi.

[5] Serban, Monica and Stoica, Melinda (2007), Politici si institutii in migratia internationala. Migratie pentru munca din Romania, Fundatia Pentru o Societate Deschisa, Bucharest.

[6] Ulrich, L, Stanciugelu, S., Bojinca, M., Mihaila, M. (2011), Al patrulea val: migratia creierelor pe ruta RomaniaOccident, Fundatia Soros Romania, Bucharest. 